Economics Working Paper Series

2019/012

\title{
Auction Mechanisms and Treasury Revenue: Evidence from the Chinese Experiment
}

\author{
Klenio Barbosa, Dakshina G. De Silva, Liyu Yang \\ and Hisayuki Yoshimoto
}

The Department of Economics

Lancaster University Management School

Lancaster LA1 4YX

UK

(C) Authors

All rights reserved. Short sections of text, not to exceed two paragraphs, may be quoted without explicit permission, provided that full acknowledgement is given. 


\title{
Auction Mechanisms and Treasury Revenue: Evidence from the Chinese Experiment*
}

\author{
Klenio Barbosa ${ }^{\dagger}$ Dakshina G. De Silva Liyu Yang $^{\ddagger}$ Hisayuki Yoshimoto
}

June 14, 2019

\begin{abstract}
This paper exploits a large-size auction experiment conducted by two Chinese Government Treasury security issuers - the Chinese Development Bank and the Export-Import Bank - to investigate whether Treasury securities should be sold through uniform or discriminatory auction mechanisms. Based on the outcomes of more than 300 Treasury securities issued through an alternating auction-rule market experiment, we find that auction outcome yield rates of the two auction formats are not statistically different, suggesting revenue equivalence. This equivalence is robust across different revenue measurements and participation behavior.
\end{abstract}

JEL Classification: C57, C58, D44.

Keywords: Treasury Security Auctions; Discriminatory Auctions; Uniform Auctions; Revenue Equivalence.

*We would like to thank Lawrence Ausubel, George Deltas, Liran Einav, Sergio Firpo, Ali Hortaçsu, Jakub Kastl, Joris Pinkse, Robert Porter, Mike Tsionas, and Giorgio Valente for their insightful suggestions. We are also grateful to all seminar and conference participants at the Auctions and Informational Economics: Theory and Econometrics workshop in Memory of Artyom Shneyerov (Paris), the Policy Research Institute at the Ministry of Finance Japan (Tokyo), Hong Kong Institute for Monetary Research, Asia-Pacific Industrial Organization Conference (Auckland), Auctions, Competition, Regulation, and Public Policy Conference (Lancaster University), Colby College, Durham University, University of Glasgow, and University of St. Andrews for their helpful comments.

†Insper Institute of Education and Research, Rua Quatá, 300, Sao Paulo (SP), 04546-042, Brazil. Email: kleniosb@insper.edu.br

${ }^{\ddagger}$ Department of Economics, Lancaster University Management School, Lancaster LA1 4YX, UK. Email: d.desilva@lancaster.ac.uk

${ }^{\S}$ Department of Economics, Lancaster University Management School, Lancaster LA1 4YX, UK. Email: l.yang13@lancaster.ac.uk

ฯUniversity of Glagow, Adam Smith Business School, Glasgow, G12 8QQ, Scotland. Email: hisayuki.yoshimoto@glasgow.ac.uk 


\section{Introduction}

Researchers around the world have long been interested in understanding which multi-unit auction format generates a lower yield rate and a higher price for bond issuers. The debate is also of public interest, as a well designed Treasury auction market could potentially generate larger revenues and reduce tax burdens. A seminal paper in the theoretical multi-unit auction literature, Ausubel et al., (2014), finds that the general revenue ranking of uniform and discriminatory auctions is ambiguous, especially when bidders are asymmetric in their type distributions and have asymmetric information. ${ }^{1}$ They emphasize that determining the revenueenhancing pricing rule is, thus, an empirical question, encouraging empirical researchers to further pursue (either counterfactual or direct) comparison of auction rule outcomes.

In this paper, we exploit an alternating-auction-rule market experiment (hereinafter the experiment) conducted between 2012 and 2015 by two large Chinese government banks - the Chinese Development Bank (CDB) and the Export-Import Bank (EIB) - to investigate the revenue ranking of uniform and discriminatory auctions. ${ }^{2}$ The experiment lasted for three years and the total value of the experiment was $¥ 1.95$ Trillion (approximately $\$ 291$ billion). Because the Treasury auction formats are alternated in the experiment, the CDB and EIB design an auction format based neither on bond characteristics, nor on financial and economic market conditions. Our summary statistics and balance tests confirm that the auction format used by the CDB and EIB to sell government bonds was not correlated with observed bond features or market conditions. Consequently, the two auction rules were used in an otherwise similar environment, that allows us to obtain unbiased estimates to assess the effect of a specific auction rule on yield rates and revenue of Treasury securities.

Using Treasury auction data gathered from the CDB and EIB experiments, we find that the uniform and discriminatory auction formats exhibit revenue equivalence. As far as we know, this study is the first to address this important empirical revenue-comparison question by directly comparing the outcomes of those two multi-unit auction rules using real market data in a large-scale market-based experiment.

We conduct our empirical analysis by investigating whether there is any difference in the

\footnotetext{
${ }^{1}$ Notably, the study of Ausubel et al. (2014) derives revenue rankings under either symmetric bidders or symmetric information settings. They also report that, by changing some model setups, such as symmetry and risk-neutral assumptions, researchers can derive different revenue rankings.

${ }^{2}$ These banks are government policy banks that finance economic policies and, for this reason, we call the securities issued by the CDB and EIB 'Chinese government bonds.' These two institutions have the same short and long credit ratings awarded by Moody's, Standard \& Poor's, and Fitch. Their credit ratings also coincide with the ones awarded by these rating agencies to other Chinese government bonds issued by the Ministry of Finance (MOF).
} 
yield rate of securities sold through discriminatory and uniform auctions during the experiment. This direct empirical comparison of yield rates is important because the theoretical literature is inconclusive regarding revenue superiority between discriminatory and uniform auctions. ${ }^{3}$ As in Hortaçsu et al. (2018), our outcome is the normalized auction yield rate, which we construct as the weighted-average auction winning rate minus the prior day's corresponding market yield of Chinese bonds based on maturity and institution. We hereafter refer to this as the 'normalized rate.' An advantage of using the normalized rate is that the market yield curve removes unobserved heterogeneity across auctions as it captures fluctuations of the economic environments. Additionally, the same security at different times may be subject to very dissimilar demand-side factors and accounting for unobservable heterogeneity at the auction level becomes crucial.

As we are exploiting a market-based experiment in our analysis, we control for bond characteristics and market conditions in all specifications. This is because, in such instances, results from a control-based estimation approach with relevant baseline variables perform better (improve efficiency and increase statistical power) and dominate the uncontrolled estimates even when observable characteristics in groups (e.g., auction format) are statistically not different (Bruhn and McKenzie, 2009).

Our ordinary least squares regression (OLS) results indicate that normalized rates are not statistically different between uniform and discriminatory auction formats, empirically suggesting revenue equivalence. Further, our OLS results show that the range of the 95 percent confidence intervals are from a minimum of [-0.081, 0.082] and a maximum of [-0.085, 0.096], depending on the empirical specification. Additionally, we estimate our empirical models using the Bayesian regression technique. In this case, our estimated posterior distribution allows us to determine an interval in which the coefficient of the dummy variable that captures the difference in the two auction formats falls with a 95 percent chance (i.e., credible interval for our parameter of interest). Based on the results, credible intervals range from a low of [-0.071, 0.052] and a high of [-0.067, 0.077], depending on the empirical model. ${ }^{4}$

\footnotetext{
${ }^{3}$ For example, Bukhchandani and Huang (1989), who proposed a multi-unit common value model of treasury auctions with resale opportunities, show that higher revenue occurs in uniform auctions compared to the discriminatory format. Back and Zender (1993) initiate the discussion that the one-shot switch from the discriminatory to the uniform auction format, which was introduced by the U.S. Treasury in the early 1990s, might have decreased the Treasury's revenue. Moreover, under a risk-neutral and symmetric information environment, Wang and Zender (2002) show a revenue advantage in discriminatory auctions compared to uniform auctions. However, they note that this revenue advantage result may flip when bidders are riskaverse.

${ }^{4}$ To the best of our knowledge, the debate over the revenue comparison is more than a half-century old, originally initiated by a series of statements by Milton Friedman (1959 and 1991). Specifically, Friedman (1991) claims that switching from the discriminatory to the uniform format would enable the US Treasury to
} 
We perform additional tests to ensure that our results are robust. First, we examine whether there is a difference in normalized rates between auction formats due to the high and low yield rates observed in discriminatory auctions. To address this concern, we re-estimate our models with the highest and lowest normalized winning bids for discriminatory auctions. We find, again, that the absence of a statistical difference between uniform and discriminatory formats holds as well for the normalized highest and lowest bids of discriminatory auctions compared to uniform auctions. Second, we investigate whether bidders are potentially aware of the alternating-rule auction format during the experiment and behave strategically by choosing the most profitable auction mechanism. Our findings suggest that bidders did not change their participation and bidding patterns throughout the experiment based on the auction format. Third, we investigate whether our results hold for the full distributions of normalized rates by re-estimating the empirical models using the quantile regression method. The results are qualitatively similar to the ones shown in the mean regressions indicating that there is no significant difference between normalized rate distributions generated by uniform and discriminatory auctions. Lastly, we examine whether there are any differences in the auction yield rates between uniform and discriminatory auctions held by the CDB and EIB individually. Our results indicate that, regardless of the institution, the revenues generated from uniform or discriminatory auctions have no statistical difference. ${ }^{5}$

A reader may question whether our point estimates on the difference in the normalized rates does correspond to the actual difference in revenues from bond issuance in the two auction formats. To address this concern, we perform an analysis to examine the change in revenue if the CDB and EIB would have issued their bonds by using uniform auctions rather than discriminatory auctions. The results from this exercise show that the potential loss/gain from issuing all bonds through the uniform auction format ranges from -0.00041 percent to 0.00054 percent of Chinese government expenditure during the three years of the experiment. These results provide evidence that the use of uniform or discriminatory auction formats does not generate any considerable economic gains.

Our research is also related to the recent empirical literature on Treasury auctions. Pioneered by the study of Hortaçsu (2002), recent studies build and estimate structural Treasury auction models and base the evaluation of different auction rules on counterfactual simulation (for instance, Hortaçsu and McAdams, 2010; Hortaçsu and Kastl, 2011). Nevertheless,

save 75 basis points.

${ }^{5}$ Additionally, we find that our results hold when we consider only non-floating bond auctions - the largest subset of bonds in our sample. 
the counterfactual results based on structural estimation do not provide clear-cut conclusions about which treasury auction rule generates a lower yield rate and larger revenue. Some studies present results in favor of uniform auctions, while others support discriminatory auctions. Another set of studies reports that the two mechanisms would generate quantitatively similar revenues. ${ }^{6}$ In addition, despite the fact that revenue equivalence is often reported in empirical studies, the ambiguous revenue ranking in the theoretical literature (e.g., Wang and Zender, 2002; Ausubel et al., 2014) does not necessarily imply revenue equivalence, which warrants careful experimental investigation.

By analyzing the one-shot auction-rule change (i.e., single time-point auction rule switching during an investigation period) introduced by the U.S. Treasury in 1973-76 and 1992-93, other studies have also investigated which auction format, uniform or discriminatory, generates a lower yield rate and a higher price for bond issuers (see Simon, 1994; Mester, 1995; Nyborg and Sundaresan, 1996; Malvey and Archibald, 1998). ${ }^{7}$ However, these studies were unable to provide unbiased estimates for the revenue ranking as the bonds issued under the two auction formats were different in several dimensions (e.g., market conditions, maturity, duration, volume, etc.). Conversely, the auction format used by the CDB and EIB to sell government bonds during the experimental period was not related to bond characteristics and market conditions, which allow our OLS and Bayesian regressions to provide unbiased estimates for the revenue equivalence of uniform and discriminatory auctions.

The experiment conducted by the CDB and EIB - the focus of this paper - enables us to directly compare the auction outcomes and revenues of Treasury securities sold through uniform and discriminatory auctions. Our findings also complement previous structural estimations and counterfactual results.

Besides providing evidence of the revenue equivalence between the two auction formats,

\footnotetext{
${ }^{6}$ Empirical literature have mixed views on the revenue comparison. Tenorio (1993), Umlauf (1993), and Armantier and Sbai (2006) report the revenue advantage of the uniform format, while Simon (1994) and Fevrier et al. (2004) support the discriminatory format. However, the most popular finding in the empirical literature - such as Nyborg and Sundaresan (1996); Malvey et al. (1998); Hortaçsu (2002); Hortaçsu and McAdams (2010); and Bonaldi, Hortaçsu, and Song (2015) — is empirical revenue equivalence with statistically insignificant differences between the two formats. Also, see the unique study of Brenner et al. (2009) which investigates revealed preferences of auction mechanism choices among approximately 50 countries.

${ }^{7}$ Specifically in 1973-76, the U.S. Treasury conducted six uniform and 10 discriminatory auctions, with the auction rule switched from the uniform to the discriminatory format in May 1974 (see Simon, 1994). Moreover, in 1992-93, the U.S. Treasury held 15 uniform auctions (of two- and five-year maturities) and 91 discriminatory auctions (of three and six months and one-, two-, three-, five- and 10-year maturities) (see Nyborg and Sundaresan, 1996). The two- and five-year maturity bond auctions were switched from discriminatory to uniform in September 1992 (see Mester, 1995). Tenorio (1993) and Kang and Puller (2008) also investigate one-shot changes from one auction format to another in Zambian foreign exchange and Korean Treasury auctions, respectively.
} 
the experiment documented in this study offers a novel research design. Other Treasuries and banks from all over the world could replicate it and assess other aspects of auction mechanisms. Such potential assessment includes the effects of asymmetric bidding behavior, set-asides, lotsize effect, uncertain supply, and tilted supply function, which go beyond the auction yield rates analyzed in this paper and have great potential to increase revenues.

The paper is organized in the following manner. In Section 2, we explain the market background and, in Section 3, we explain the experiment and the data. Section 4 presents the auction market. We discuss our results in Section 5 and, in Section 6, we assess the revenue equivalence. The conclusion is presented in Section 7.

\section{Market background}

In this section, we first introduce the two government policy-bank bond issuers - the CDB and the EIB - which conducted the alternating rule experiment in the People's Republic of China (henceforth, PRC). We then present the credit ratings of these two institutions, showing that they have identical ratings. Lastly, we explain the yield curve of each institution's securities, which is publicly announced each business day.

\subsection{Two government security issuers (CDB and EIB)}

The two bond issuers investigated here are the CDB and the EIB. The CDB issues bonds to finance national development projects initiated by the government for both domestic and foreign projects, while the EIB auctions off bonds to raise funds for projects related to exports and high-tech industries. A detailed explanation of the historical background of these two institutions is provided in Barbosa et al. (2018).

\subsection{Credit ratings}

The CDB's and EIB's short- and long-term ratings are listed in Table 1. The credit ratings are awarded by three foreign agencies: Moody's, Standard \& Poor's, and Fitch. In this table, we also list the ratings of government securities issued by the Ministry of Finance (MOF) as a benchmark reference. We find that all institutions have homogeneous credit ratings within each year, indicating that, from the viewpoint of the rating agencies, all of these government securities are categorized equivalently. 
The credit ratings of these government banks are homogenous because their bonds are backed by the PRC (see Chen, 2014, for details). Further, bond market participants perceive that the bonds issued by these institutions are fully backed by the Chinese government (Chen, 2010; Li, 2014)..$^{8,9}$ As a consequence, the CDB and EIB historically have the same credit ratings, enabling us to compare auction outcomes across institutions. Finally, although credit ratings were awarded to these bond-issuing institutions (i.e., institutional ratings), there is no credit rating for each government security. As far as we know, these institutions had not solicited any credit analyses from rating agencies prior to 2017.

\section{$2.3 \quad$ Yield curves}

We use the market yield curve to normalize the bond-level auction yield rates and as a proxy for market conditions. The market yield data are obtained from the China Central Depository \& Clearing Co., Ltd. (CCDC). The CCDC is a State Council-approved agency (also authorized by the China Banking Regulatory Commission) that records all government bond-related transactions.

Based on previous resale market transactions, the CCDC publicly announces the yield curves for bonds issued by each institution and maturity on every business day. These yield curves provide official benchmarks to general investors. ${ }^{10}$ Moreover, resale market yield rates, especially for short-term bonds, experience significant volatility and convey information about market conditions. Hence, in our regression analyses, we use the variance of the yield curve in the period from five days before the auction date to control for the volatility in the Chinese bond market. ${ }^{11}$

\footnotetext{
${ }^{8}$ The People's Bank of China (the central bank), which governs the CDB and EIB, operates directly under the government. Additionally, the MOF operates directly under the State Council.

${ }^{9}$ See Jian Chen (2014), China Finance Publishing House, "Research on the Financial Bonds issued by Policy Banks in the Process of Reform and Transition (Gai ge zhuan xin zhong de zheng ce xing yin hang jing rong zai quan yan jiu)" for political-economic background on the CDB and EIB, indicating that they have Chinese government-guaranteed sovereign credit ratings. Also see Ying Chen (2010), Finance Teaching and Research, "Suggestions to Current Credit Rating of Chinese Bonds (Dang qian wo guo xing yong ping ji de wen ti ji dui ce jian yi)" and Haitao Li (2014), South Journal, "Research on Development of Credit Rating System in Chinese Bond Market (Wo guo zai quan shi chang xing yong ping ji zhi du fa zhan yan jiu)" for details on credit rating equivalence.

${ }^{10}$ To our knowledge, there are no other benchmark yield curves publicly announced in China.

${ }^{11}$ The variance is separately derived for each institution by the corresponding maturity of the auctioned security.
} 


\section{The experiment}

For the periods of May 2012-July 2014 and July 2013-May 2015, the CDB and EIB alternated between the discriminatory and uniform pricing auction formats. The CDB held their weekly (or bi-weekly) auctions on Tuesdays, while the EIB typically held their bi-weekly (or often less frequent) auctions on Fridays. On an auction date, these institutions usually held multiple auctions with bonds of varying maturities. ${ }^{12}$ During these market-based experiment periods, the institutions controlled the auction formats, alternating between them, but the experiment was not publicly announced. Most importantly, the auction rule choices made by the CDB and EIB cannot conceivably be correlated with the observed and unobserved bond characteristics or with financial market variables in our regression models. As we will show, in Section 5, observable bond characteristics and financial and economic market conditions are not correlated with the auction format.

\subsection{CDB experiment}

During the experimentation period, the CDB conducted a total of 269 auctions. Out of these, 139 were uniform and 130 were discriminatory (see Table 2). Within each (bi-)week, the CDB auctioned off bonds of different maturities (two-, three-, five-, and seven-year) with varying auction rules. ${ }^{13}$ A stylized pattern of this experimentation is shown in Table 3 . As the table shows, the auction mechanism alternated between discriminatory and uniform auction rules (for example, see discriminatory auctions on 22 January 2013 and uniform auctions on 29 January 2013). Additionally, for some weeks, the CDB set the discriminatory format for three- and seven-year maturity notes, and the uniform format for five-year notes. However, in the following (bi-) week, all maturities were sold through the uniform auction format.

\subsection{EIB experiment}

Similarly, the EIB also experimented with their security auction rules. From July 2013 to May 2015, the EIB held 79 auctions: 49 using the uniform format and 30 using the discriminatory format (see Table 2). Although the alternating auction-rule pattern is not as stylized as that used by the CDB due to fewer and relatively infrequent auctions, the pattern of the EIB's

\footnotetext{
${ }^{12}$ For instance, on April 8th, 2014 (Tuesday, a bid submission date), the CDB auctioned off four types of securities - with one-, two-, three-, five-, and seven-year maturities - through separate auctions.

${ }^{13}$ Note that, in addition to the two-, three-, five- and seven-year notes, one-year bills and ten-years notes were also auctioned off by the CDB. These were always sold through the uniform-pricing format. For this reason, one-year and 10-year securities are excluded from our regression analyses.
} 
auction rule experiment is as follows. The EIB conducted bi-weekly (or often less frequent) auctions, held typically on Fridays. The EIB alternated the two different auction rules for different maturities (see Table 3, Panel A) and, in the latter half of the experimental period, the EIB used the both auction rules for bonds of the same type when reissuing them (see Table 3, Panel B). ${ }^{14}$

\subsection{The timing of auction-rule announcements}

During the experimental period of 2012-2015, the CDB and EIB were required to follow strict security issuance guidelines set by the People's Bank of China. ${ }^{15}$ Accordingly, the CDB and EIB made auction-rule announcements three business days in advance. This means that the participants knew which format was going to be used for a given auction only three business days before the auction date. To illustrate what was known by auction participants at the auction, consider the following example. Let us suppose that auctions are held every Tuesday and we consider two auctions in two consecutive weeks. Once the first auction's transactions are settled, the outcome of the auction is made public on Wednesday. Then, institutions announce the specific details of the second auction (e.g. auction date, volume, mechanism, corresponding maturity, etc.) on Thursday. ${ }^{16,17}$ Hence, ex-ante, bidders do not know the specific date, volume, and maturity of upcoming auctions nor associated future auction formats. Hence, based on the time of the announcement, bidders cannot condition their current bids on future auction rules. ${ }^{18}$

\footnotetext{
${ }^{14}$ Note that, when reissued, each bond received a new ID. As we know the old bond ID, we can identify the reissue of an old bond.

${ }^{15}$ Source: Official Notice of People's Bank of China (2009), "Administrative Procedures for the Issuance of Financial Bonds in the National Inter-Bank Bond Market (Quan guo yin hang jian shi chang jin rong zhai quan fa xing guan li chao zuo gui cheng)." In these guidelines, a regulation explicitly states that the public notice of a new issuance auction (which includes the auction rule and other information, such as maturity, volume, issue date, etc.) has to be made at least three business days in advance. To the best of our knowledge, there was no annual, quarterly, or monthly issuance/auction schedule announcement made by the CDB and EIB during their experimental periods.

${ }^{16} \mathrm{~A}$ small number of deviations from these stylized announcement patterns were made when there was a long interval between two consecutive auction dates, or in the event of a public holiday.

${ }^{17}$ Specifically, the CDB made a public announcement of the auction rule on a Thursday and bids were submitted on the Tuesday of the following week. The EIB made a public announcement, typically on a Tuesday, and bids were submitted on the Friday of the same week.

${ }^{18}$ We collected data on the public notice date of each auction and issuance. Our data confirm that the CDB and EIB followed the guidelines set by the People's Bank of China.
} 


\section{Auction market data}

We obtain data on auction activities in the Chinese bond market from two data sources, the Wind Database and Chinabond.com. The Wind Database is maintained by the Wind Information Co. Ltd., a financial data and information provider in China. Chinabond.com is the official website of the China Central Depository \& Clearing Co. Ltd., which is the only government bond depository authorized by the MOF and is responsible for the establishment and operation of the government bond depository system.

The Wind Database provides access to the details of the CDB and EIB bond auctions. Our data contain not only the information of auctioned bonds, such as maturity, auction method, size of auction, and tender subjects (e.g., price or yield), but also the auction outcomes of weighted-average winning yield rate (or price), total demand, number of bidders, number of bids, number of winning bids, number of winners, final coupon rate for each auction, the presence or absence of floating coupons, as well as the highest and the lowest winning rate in discriminatory auctions. We collect supplementary information from Chinabond.com such as bond types, subsidies, coupon payment, and the date of each bond issued by the CDB and EIB.

Our data provide information at the auction-level. Bid-level data with the identity of bidders are not available due to the restrictive nature of Chinese bond market data. Nevertheless, the data generated from the experiment contain information on Treasury security yield rates for the two auction formats that is used to answer the revenue ranking question in the literature.

\subsection{Auction rules and market conditions}

A potential concern about our empirical strategy would be the possible correlation between auction formats, bond features, and market conditions. If a specific auction rule is endogenously chosen when the financial market experiences a specific circumstance, then our estimates would be biased despite using experimental data. There are three important reasons why the auction formats are not correlated to unobserved bond and market characteristics. First, under the (bi-) weekly alternating nature of the auction rules, as well as the strictly

regulated timing of the auction announcements, it is not plausible that the unobserved bond characteristics, nor present and future financial and economic market conditions, have room to influence the auction rule. Second, systematic changes in financial market conditions do not normally occur on a (bi-) weekly basis. Lastly, during the experimental period of the EIB 
(described above) two auction rules were used within the same week. Also, note that the differenced construction of the normalized yields prevents unobserved characteristics entering into our regression models.

We find statistical evidence that the respective auction rules are not associated with any specific bond type, nor are they chosen to match specific financial conditions. Table 5 reports summary statistics for observables associated with the uniform and discriminatory auctions. In this table, we show the mean of the prior day's yield curve, the maturity of the auctioned security, market volatility, and the value of maturing bonds by institution for a given month. Similarly to Park and Reinganum (1986) and Ogden (1987), we also include an indicator variable that captures whether the auction date takes place seven days before or seven days after the end of the month. This control variable captures large financial transactions concentrated at the end of the month, as financial institutions prefer to keep a relatively large liquidity at that time. In Table 5, we also provide 95 percent confidence intervals and calculated $t$ values. The results show that these variables are not statistically different between uniform and discriminatory auctions, indicating that bond characteristics and financial market conditions were well-balanced during the experiment. For example, the average market yield rate of Chinese bonds one day before the auction date is 3.685 percent for uniform auctions, while it is 3.683 percent for discriminatory auctions. The 95 percent confidence intervals clearly overlap between uniform and discriminatory auctions and the calculated $t$-value is 0.044. Similar conclusions are derived for other variables presented in Table 5. These results hold for 90 percent confidence intervals as well. ${ }^{19}$

Considering other regression variables, the timing between two auctions in the institutions is about 8.5 days, and the demand-to-supply ratio is 2.5. In our sample, we observe 47 floating bonds, which represent about 13.5 percent of all auctions. Note that these floating bonds were issued only by CDB through uniform auctions. Our baseline estimates use all auctions, including the floating ones. However, in Section 5.2, we report results without these 47 floating bond auctions and show that these results are qualitatively the same as the ones using the full sample. Full descriptions of the variables used in the analysis are presented in Table A-1.

\footnotetext{
${ }^{19}$ In addition to the $t$-test, we perform a Kolmogorov-Smirnov (KS) test to evaluate the equality of distributions of each variable by auction type. In all cases, we fail to reject that distributions are equal by auction format. Note that we omitted the comparison of the maturities, as the maturity variables are classified into several discrete categories (e.g., two-year, three-year, etc.), and are not compatible with the framework of KS distributional equivalence tests.
} 


\subsection{Auction rules and number of bidders}

Another concern is the equality of the number of bidders in these two auction formats during the experiment. It is worth noting that, to bid in the primary market, bidders have to be prequalified. Primary market bidders have to go through a rigorous prequalification process and past performance influences the continuation as a primary dealer in the following year. On average, during the experimental period, the CDB had about 76 pre-qualified bidders while the EIB had about 66. Additionally, we observe that more than 90 percent of dealers continue from year to year during the experiment period at each institution. Considering new entrants, the CDB and EIB had about six and five new entrants, respectively, every year during this period. More importantly, on average, about 88 percent of primary dealers participate in the auctions of both institutions. We observe a similar pattern for the pre- and post-experimental period. More detailed information can be found in Barbosa et al. (2018). However, the CDB and EIB enforce neither mandatory participation nor purchasing volume requirement. Hence, we examine bidders' participation behavior during the experiment period. In this case, we estimate the following equation:

$$
n_{i j t}=\gamma D_{i j t}+X_{i j t}^{\prime} \varphi+\alpha_{j}+\tau_{t}+u_{i j t}
$$

where our dependent variable is the number of bidders in an auction $i$ sold by an institution $j$ at a given time $t$. The indicator variable, $D$, controls for the auction mechanism $(D=1$ for discriminatory auctions). Other observable characteristics, such as time gap between auctions by institution, demand-to-supply ratio of bonds, duration of the bond sold, and market conditions, are represented by the vector $X$. Institution effects and time effects are denoted by $\alpha$ and $\tau$ respectively and $u$ is the error term.

Given that the number of bidders is a count, we estimate Equation (1) using the Poisson Pseudo Maximum Likelihood (PPML) method. ${ }^{20}$ We also estimate the above model using OLS. Table 6 reports these results with and without floating bonds. Our main interest is in the coefficient of the auction mechanism dummy. Our results show that there is no statistical difference in the number of bidders based on auction rule during the experimental period.

Hence, conditional on controls, this experimental environment enables us to conceivably interpret the auction rule variable as conditional mean-independent, treating it as exogenously assigned. Taken all together, the Treasury auction experimental environment in China is quite

\footnotetext{
${ }^{20}$ For PPML estimation, the data does not have to follow a Poisson distribution to produce consistent estimates. The only condition required for consistency is the correct specification of the conditional mean of the independent variable (see Santos Silva and Tenreyro, 2006, 2010; Wooldridge, 1999).
} 
advantageous to directly comparing the revenues generated from uniform and discriminatory auctions. In the next section, we conduct our empirical analysis by investigating whether there is any difference in the yield rate of the CDB and EIB securities sold through discriminatory and uniform auctions.

\section{Estimation results}

\subsection{Revenue ranking}

To assess the revenue ranking of uniform and discriminatory auctions, we consider the following empirical model:

$$
y_{i j t}=\beta D_{i j t}+X_{i j t}^{\prime} \phi+\alpha_{j}+\tau_{t}+\epsilon_{i j t}
$$

where our dependent variable, $y$, is the normalized yield rate for a given auction $i$, from institution $j$, in period $t$. The variable $D$ is a dummy variable which identifies the auction mechanism as described before. The coefficient $\beta$ identifies the difference in normalized rates generated from uniform and discriminatory auctions. We also include other controls $(X)$ as described before. The error term is denoted by $\epsilon$ while $\alpha$ and $\tau$ are institution and time effects.

We estimate the parameters in Equation (2) using two different estimation methods. First, we conduct our empirical analysis using the ordinary least squares (OLS) approach. Second, we use a Markov-Chain-Monte-Carlo (MCMC) technique based on a hybrid MetropolisHastings sampling scheme with Gibbs updates to estimate our posterior mean and posterior standard deviations of the parameters in Equation (2). OLS results are presented in the first three columns of Table 7, while Bayesian results are presented in the last three columns.

In all our Bayesian regressions, we use uniform priors for the regression coefficients and an inverse-gamma prior with shape and scale parameters of 0.1 for the error variance. Further, we implement 22,500 iterations, and the first 2,500 are omitted to mitigate possible start-up effects. ${ }^{21}$ This Bayesian approach offers several considerable advantages. First, the MCMC gives us the finite-sample properties of the resulting estimates, rather than asymptotic approximations. Second, incorporating a non-parametric unobserved heterogeneity component makes the specification of the model more flexible and, hence, the results more robust (Li and Zheng, 2009). However, in practice, one must verify the convergence of MCMC before

\footnotetext{
${ }^{21}$ Gelman et al.,(2004) provide a detailed description of the Bayesian method, including conditional distributions and the uniform prior distributions used in this paper.
} 
making any inferential conclusions about the obtained results. In our exercise, we see that the posterior distribution looks normal. The kernel density estimates based on the first and second halves of the sample are very similar to each other and are close to the overall density estimate. Both approaches provide an unbiased and consistent estimate for $\beta$ when auction rule variable $D$ is exogenously determined, as in our case.

In our base model, presented in Column 1 of Table 7, we regress the normalized yield rate on a parsimonious model with an indicator for discriminatory auctions, floating bonds, monthly effects, year effects, and market drift term. Controlling monthly and year effects are important because the government objectives or budgets could change yearly and/or the promotion of high-tech industries may vary by season. For example, it is quite common to promote new television models in November or December than in July or August. Given the well-balanced experiment conducted by the CDB and EIB, described in Section 4 (Tables 5 and 6), the estimations from this simple OLS regression provide unbiased estimates. Our estimated coefficient from this regression indicates that normalized winning rates for uniform and discriminatory auctions are statistically not different and are close to zero. This shows that revenue-equivalence results hold even without controlling for additional observable auction characteristics and market conditions.

Given that we are exploiting a market-based experiment, in our other specifications we control for bond characteristics and market conditions to examine the revenue ranking. As Bruhn and McKenzie (2009) have pointed out, in such non-laboratory experiments, a control-based estimation approach with relevant baseline variables improves efficiency, increases statistical power, and dominates the uncontrolled estimates even when observable characteristics in groups (e.g., discriminatory vs. uniform auctions) are not statistically different.

Hence, in Column 2 of Table 7, we include additional controls for auction and financial market conditions. Specifically, we do so in Column 2 and in all subsequent models (excluding Column 4) as we pool the observations from the CDB and EIB auctions. We also include bond-issuer fixed effects to account for any difference between bonds of different issuers that goes beyond their credit risk. In Columns 3 and 6, we include the number of bidders in addition to other controls. Overall, our results indicate that there is no statistical difference between uniform and discriminatory auctions' normalized yield rates. From our estimations in Table 7, the coefficients of the discriminatory auction dummy are close to zero. They vary from -0.006 percent $(-0.6 \mathrm{bps})$ to 0.008 percent $(0.8 \mathrm{bps})$, which corresponds to -0.001 percent and 0.002 percent of the mean auction rate of the bonds in our sample (the mean auction rate is 4.394 percent, i.e., 439.4 bps). In general, regardless of the estimation method, 
our results indicate that the estimated yield rate difference generated between uniform and discriminatory auctions is close to zero and has no statistical significance.

\subsection{Robustness tests}

\subsubsection{High and low auction rates in discriminatory auctions}

In the previous estimation, we consider only the auction-specific normalized weighted average winning bids. One could argue that the difference between auction formats might differ when we measure outcomes with the highest or the lowest accepted auction rates observed in discriminatory auctions. To address this concern, we re-estimate our models with the normalized highest and lowest winning primary bids for discriminatory auctions using the specification in Column 3 for OLS regression and in Column 6 for Bayesian estimation. Note that, in discriminatory auctions, the average range between the normalized highest and lowest winning bids is 0.032 percent with a standard deviation of 0.026 .

In Table 8, we report the results for normalized weighted-average auction winning ratebased uniform auctions and highest and lowest winning bids of discriminatory auctions. The first two columns in Table 8 report the OLS estimation results, and the last two columns report the results of the Bayesian estimation. The results indicate that our main findingthat there is no statistical difference between uniform and discriminatory formats-holds true for the normalized highest and lowest bids of discriminatory auctions compared to uniform auctions as well.

\subsubsection{Restricted sample: without floating bonds}

As mentioned before, we observed 47 floating bonds, auctioned off using only the uniform auction format. As a robustness check, we drop these 47 auctions and re-estimate our main empirical models. We report OLS results in the first three columns and Bayesian results in the last three columns of Table 9. The first and the fourth columns report results for normalized weighted-average normalized rates for uniform and discriminatory auctions. In Columns 2 and 5, we report results using the normalized highest bids while, in Columns 3 and 6, we report the normalized lowest bids of discriminatory auctions. In all columns, we estimate the full model described in Columns 3 and 6 in Table 7. As in our earlier estimations, results indicate that there is no statistical difference between normalized rates generated from uniform and discriminatory auctions. 


\subsubsection{Bidders' behavior in alternating auctions}

Next, given that the CDB and EIB alternated between the two auction formats with remarkable regularity for three years, one could argue that bidders (financial institutions that participate in the primary market) could have been aware of the upcoming auction formats and, therefore, waited for the auction format that was most profitable to them. To test this potential threat to our research design, we conduct a number of exercises.

First, one may note that, if bidders wait for the format that is most favorable to them, they will behave differently in the first half of the experiment (when they are unaware that the issuing banks are alternating the auction formats) compared to the second half (after realizing the pattern of the experiment). To test this, we divide the CDB and EIB data into two periods - the first and second half of the experiment. We again estimate similar empirical models presented in Table 7, Columns 2, 3, 5, and 6. Our results are presented in Table 10 and indicate that there is no statistical difference between uniform and discriminatory auction yields in the first or the second half of the experiment. This suggests that bidders did not change their bidding patterns throughout the experiment.

Next, we record bidder participation by examining the average number of bidders by auction type during the experiment. During the experiment, the uniform auctions attracted 34.30 (5.82) bidders on average per auction, while discriminatory auctions attracted 35.88 (4.88) bidders on average (standard deviations are in parentheses). When considering the average number of bidders by institution, the CDB averaged 33.99 (5.26) bidders per auction, while the EIB averaged $38.54(4.56){ }^{22}$

In Figure 1, we have plotted the weekly average of the number of bidders per auction for all Treasury notes by auction mechanism during the experiment. One can observe that both auction types have similar patterns for the average number of bidders per auction. If bidders were using a dynamic waiting strategy, the number of participants in discriminatory and uniform auctions would move in opposite directions throughout the auction series. The figure does not reveal such a counter-cyclical movement pattern. Instead, it shows that the number of bidders remains similar across auction formats during the experimental period, indicating that bidders did not wait for their preferred auction format. ${ }^{23}$

\footnotetext{
${ }^{22}$ There were no Treasury instruments with maturities greater than one year or less than 10 years (Treasury notes) sold using the discriminatory auction format before or after the experiment by either institution. For this reason, we cannot compare the number of bidders per auction before, after, and during the experimental period.

${ }^{23}$ Kang and Puller (2008) conclude that, in Korean Treasury auctions, there is a slight revenue advantage for the discriminatory format, but the revenue difference between the two formats is quite small due to the competitiveness of the market. The average number of bidders in Korean auctions is smaller than in Chinese
} 
In addition to this, we formally test whether there is a difference in the number of bidders in the first and second half of the experiment depending on the auction format. We regress the number of bidders on the auction mechanism dummy, a variable that indicates that the auction is let during the second half (second half indicator) and also on another variable that captures the difference between uniform and discriminatory auctions in the second half (second half indicator $\times$ discriminatory auction indicator). We also control for observable auction and market characteristics. In Table 11, we report estimations using the Poisson Pseudo Maximum Likelihood (PPML) method in Column 1, and the OLS method in Column 2. All our estimated results in Table 11 indicate that there is no statistical difference between the number of bidders in uniform and discriminatory auctions in the first and second period.

Another possible way to examine the robustness of bidder participation and normalized rates results is to investigate the differences of these outcomes just before and after the experiment. However, such a comprehensive investigation is not possible as the CDB and the EIB did not use discriminatory auctions prior to or following the experiment period. Alternatively, we compare the bidder participation and auction yield outcomes in uniform auctions during and 12 months after the experiment period. Our results indicate that the bidders did not behave differently during and after the experiment period (See Table A2 in the appendix). ${ }^{24}$

These exercises further support the notion that bidders (i) did not discriminate between auction formats as part of a static participation or dynamic waiting strategy, due to the rigidly framed non-overlapping auction announcement cycles, and (ii) did not behave differently during and after the experiment period. It is worth noting that, as the institutions neither officially nor publicly announced the end date of the experiment, the CDB and EIB could have stopped the experiment at any given time, making a potential forward-looking waiting strategy impossible for bidders.

\subsubsection{Effect on the distribution of bids}

A potential concern is that our results may not hold for the full distribution of the normalized weighted average outcome of the yield. To address this issue, we re-estimate the empirical auctions and, hence, the Chinese market could be considered more competitive than the Korean market. Note that, on average, the Korean auctions have about seven and 10 less bidders in uniform and discriminatory auctions, respectively, compared to similar Chinese auctions.

${ }^{24}$ In principle, we could examine whether there were any differences in bidder entry and auction outcomes focusing only on uniform auctions. However, such a comparison faces challenges, as before the experiment period, auctions were much less frequent and had smaller volumes. As a natural consequence of less-frequent trading opportunities, the number of participating bidders and outcome yields were relatively higher before the experiment period, making the direct comparison challenging. 
models using the quantile regression method for the $15^{\text {th }}, 25^{\text {th }}, 50^{\text {th }}, 75^{\text {th }}$, and $85^{\text {th }}$ quantiles. We present these estimated results in Table 12. Note that these empirical specifications are similar to the ones presented in Table 7, Column 3. The results are qualitatively similar to the ones shown in the OLS tables and indicate that there is no significant difference between outcomes generated from the two auction formats (Panel A). In Panel B, we report results using the normalized highest yield while, in Panel C, we report the normalized lowest yield of discriminatory auctions. We also estimate these specifications without floating bids, obtaining qualitatively similar results that indicate that there is no statistical difference between normalized rates based on auction formats. These results are not presented in this paper, but can be provided upon request. ${ }^{25}$

\subsubsection{CDB vs. EIB}

During our sample period, the experiments were conducted by the two institutions separately. Hence, we next examine whether there are any differences in the normalized rates between uniform and discriminatory auctions by institution. To do this, we re-estimate the models presented in Table 7, Columns 3 and 6, by institution. The results are presented in Table 13. Columns 1 and 2, present the OLS results for the CDB with and without floating bonds. In Column 3, we report the OLS results for the EIB. Columns 4-6, present the Bayesian results for the normalized rates. All columns indicate that, regardless of the institution, the revenues generated from the two auction mechanisms have no statistical difference.

\section{Assessing revenue equivalence}

In the previous section, we have shown that the normalized yield rates are not statistically different across the two auction formats. However, the point estimates are not perfectly equal to zero and the very large monetary value involved in Treasury auctions may cause readers to wonder about the exact size of the revenue gap created by the different auction formats. In order to answer this practical question, we investigate whether the bond issuers would experience any economically relevant change in its revenue if they switched from one auction format to the other.

We use the point-estimates of the difference in the normalized rates reported by the dis-

\footnotetext{
${ }^{25} \mathrm{~A}$ minor exception is that, in Panel C Table 14, when comparing the lowest normalized winning bids of discriminatory auctions with normalized uniform winning bid rates, we observe that the discriminatory auction rate is lower by $-0.060 \%(-6.00 \mathrm{bps})$ compared to uniform auctions in the $85^{\text {th }}$ quantile.
} 
criminatory auction dummy, $\beta$, in Table 7 to estimate the change in CDB and EIB revenue if they issued their bonds using a uniform auction rather than a discriminatory one. We then compute the percentage change in the total revenue and the total change in the revenue with respect to Chinese government expenditure during the three years of the experiment (2013-2015) for each column.

For each institution, we first derive its total bond revenue by calculating the summation of all bonds that were auctioned off using uniform or discriminatory auctions. Next, we compute the total revenue if all bonds were sold through uniform auctions by replacing the price $\left(p_{i}\right)$ of each bond issued by discriminatory auctions with its counterfactual price $\left(p_{i}^{c}\right)$, which is its equivalent price if that bond was auctioned off through a uniform format. Accordingly, the counterfactual total revenue, $T R^{c}$, is then given by:

$$
T R^{c}=\sum_{i \in u a} p_{i} q_{i}+\sum_{i \in d a} p_{i}^{c} q_{i}
$$

where $p_{i}$ and $q_{i}$ are the observed prices and quantities for each bond in auction $i$, and $u a$ and $d a$ respectively refer to the subsets of bonds which were auctioned off using uniform or discriminatory mechanisms.

To obtain $T R^{c}$, we need to compute $p_{i}^{c}$ using the estimated difference in the normalized rates, $\beta$, reported in Table 7 . Adopting fixed-income pricing theory to our setting, we can write the $p_{i}^{c}$ of a bond that was hypothetically issued through a discriminatory auction as:

$$
p_{i}^{c}=\sum_{i \in m} \frac{k \times V}{(1+\text { yield }+ \text { spread }-\beta)^{m}}+\frac{V}{(1+\text { yield }+ \text { spread }-\beta)^{m}},
$$

where $m$ is the number of coupon periods of the bond (i.e., its maturity), $k$ is the periodical coupon rate payment on the maturity value $V$, yield is the period market yield rate, and spread is the margin over the market yield curve for a bond issued in a discriminatory auction. ${ }^{26}$ For the CDB and EIB, the maturity value, $V$, of every bond is equal to $100 \mathrm{RMB}$. Note that, at the time of issuance, the yield + spread corresponds to the coupon rate, which makes the issue price of each bond equal to 100 RMB. To compute the counterfactual price $p_{i}^{c}$, we calculate the present value of the expected cash flow by subtracting the estimated $\beta$ from the spread.

Now, with $p_{i}^{c}$ computed from Equation (4), we can use Equation (3) to obtain the change in total revenue. In Table 14, we present the results from this exercise. The first row shows the estimated difference in the normalized rates, $\beta$, reported in Table 7 . In the second and

\footnotetext{
${ }^{26}$ For example, see Fabozzi (2015).
} 
third rows in each column, we respectively report the percentage change in the total revenue and the total change in revenue with respect to Chinese government expenditure during the three years of the experiment.

The results in Table 14 reveal that the percentage change in the total revenue, if the bond issuers have issued all their bonds using a uniform auction, ranges from - 0.012 percent to 0.016 percent at the mean. Further, the potential loss or gain from issuing all the EIB and CDB bonds through a uniform auction ranges from -0.00041 percent to 0.00054 percent of the Chinese government expenditure during the three years of the experiment, which is negligible.

\section{Conclusion}

We exploit a large auction experiment conducted by two Chinese Government Treasury security issuers - the CDB and the EIB - to investigate whether treasury securities should be sold through uniform or discriminatory auction mechanisms. We find that auction outcome yield rates are not statistically different between the two auction formats, empirically suggesting revenue equivalence. Further, our results suggest that bidders do not reveal any preference for one format over the other.

Our observed empirical revenue equivalence results are connected to preceding influential works as recent developments in the structural Treasury auction literature provide insightful views on market design. For instance, Hortaçsu and McAdams (2010) report that, in their counterfactual simulation of Turkish Treasury auctions, switching from the discriminatory to the uniform format does not significantly increase revenue. Their simulation result is quite similar to our finding. In fact, their empirical finding is quite robust as they estimate and counterfactually calculate the upper and lower bounds of a marginal value distribution. In addition, Bonaldi, Hortaçsu, and Song (2015) report that, in the Federal Reserve's MortgageBacked Security auctions, there is a "negligible" revenue difference between the discriminatory format and truthful bidding uniform price auction (which works as a benchmark in their study) with mixed directions of revenue change when they counterfactually simulate each auction. Our direct comparison with alternating auction rules complements these prominent counterfactual studies by adding market-based experimental support for empirical revenue equivalence between uniform and discriminatory auctions.

Although the Chinese experiment enables us to directly compare auction outcomes and provide inferences on which Treasury auction rule generates a lower yield rate (larger revenues), our study has some limitations. Specifically, the lack of bid-level data with information 
about the identity of bidders prevents us from studying some aspects of market design, such as asymmetric bidding behavior with heterogeneous costs, informational advantage with primary dealership, and allocative efficiencies, which researchers actively investigate these days (e.g., Cassola, Hortacsu, and Kastl, 2013; Hortacsu, Kastl, and Zhang, 2018; Bonaldi, Hortacsu, and Song, 2015). However, one of the contributions of this study is that an alternating auction rule experiment has the legitimate potential to uncover underlying economic incentives. Thus, we leave an investigation of these advanced topics to future researchers, who can exploit Treasury auction bid data with alternating auction rules. 


\section{References}

[1] Armantier, O., and Sbai, E. (2006). Estimation and comparison of treasury auction formats when bidders are asymmetric. Journal of Applied Econometrics, 21(6), 745-779.

[2] Ausubel, L. M., Cramton, P., Pycia, M., Rostek, M., and Weretka, M. (2014). Demand reduction and inefficiency in multi-unit auctions. Review of Economic Studies, 81(4), 1366-1400.

[3] Back, K., and Zender, J.F. (1993). Auctions of Divisible Goods: On the Rationale for the Treasury Experiment. The Review of Financial Studies, 6(4), 733-764.

[4] Barbosa, K., De Silva, D.G., Yang, L., and Yoshimoto, H. (2018). Winner's Curse in Treasury Bond Markets, Lancaster University, Mimeo.

[5] Bonaldi, P., Hortaçsu, A., and Song, Z. (2015). An Empirical Test of Auction Efficiency: Evidence from MBS Auctions of the Federal Reserve. Working paper 2015-082, Federal Reserve Board, Washington, D.C.

[6] Brenner, M., Galai, D., and Sade, O. (2009). Sovereign debt auctions: Uniform or discriminatory? Journal of Monetary Economics, 56(2), 267-274.

[7] Bruhn, M. and McKenzie, D., (2009). In Pursuit of Balance: Randomization in Practice in Development Field Experiments, American Economic Journal: Applied Economics, 1 (4), 200-232.

[8] Bukhchandani, S., and Huang, C. F. (1989). Auctions with resale markets: An exploratory model of treasury bill markets. Review of Financial Studies, 2(3), 311-339.

[9] Chen, Jian (2014), Research on the Financial Bonds issued by Policy Banks in the Process of Reform and Transition. Zhong guo jing rong chu ban she, Li xing Press, China.

[10] Fabozzi, Frank J. (2015). Bond Markets, Analysis, and Strategies, 9th Edition, Pearson.

[11] Fevrier, P., Préget, R., and Visser, M. (2002). Econometrics of share auctions. Working Papers 2002-09, Center for Research in Economics and Statistics.

[12] Friedman, M. (1959). October. Testimony in Employment, Growth, and Price Levels. Hearings before the Joint Economic Committee. In 86th Congress, 1st Session, October (Vol. 30, pp. 3032-3026). 
[13] Friedman, M. (1991). How to sell government securities. Wall Street Journal, August 28.

[14] Gelman, J. Carlin, H. Stern, and Rubin. D., (2004). Bayesian Data Analysis. Chapman and Hall/CRC, 2nd ed. edition.

[15] Gordy, M.B. (1999). Hedging winner's curse with multiple bids: evidence from the Portuguese treasury bill auction. Review of Economics and Statistics, 81(3), 448-465.

[16] Goldreich, D. (2007). Underpricing in discriminatory and uniform-price Treasury auctions. Journal of Financial and Quantitative Analysis, 42(2), 443-466.

[17] Hortaçsu, A. (2002). Bidding behavior in divisible good auctions: theory and evidence from the Turkish Treasury auction market. University of Chicago.

[18] Hortaçsu, A., and Kastl, J. (2011). Testing for Common Values in Canadian Treasury Bill Auctions. Discussion paper, Stanford Instititute for Economic Policy Research.

[19] Hortaçsu, A., Kastl, J., and Zhang, A., (2018). Bid Shading and Bidder Surplus in U.S. Treasury Auctions, American Economic Review, 108 (1),147-169.

[20] Hortaçsu, A., and McAdams, D. (2010). Mechanism choice and strategic bidding in divisible good auctions: An empirical analysis of the turkish treasury auction market. Journal of Political Economy, 118(5), 833-865.

[21] Kang, B. S., and Puller, S. L. (2008). The effect of auction format on efficiency and revenue in divisible goods auctions: A test using Korean treasury auctions. The Journal of Industrial Economics, 56(2), 290-332.

[22] Li, T. and Zheng, X., (2009). Entry and Competition Effects in First-Price Auctions: Theory and Evidence from Procurement Auctions. Review of Economic Studies, 76 (4), $1397-1429$.

[23] Malvey, P. F., and Archibald, C. M. (1998). Uniform-price auctions: Update of the Treasury experience. US Treasury.

[24] Mester, L. J. (1995). Theres More than One Way to Sell a Security: the Treasurys Auction Experiment. Federal Reserve Bank of Philadelphia Business Review, July/August, 3.

[25] Nyborg, K. G., and Sundaresan, S. (1996). Discriminatory versus uniform Treasury auctions: Evidence from when-issued transactions. Journal of Financial Economics, 42(1), 63-104. 
[26] Ogden, J. P., (1987). The end of the month as a preferred habitat: A test of operational efficiency in the money market. Journal of Financial and Quantitative Analysis, 22(3), 329-343.

[27] Park, S.Y. and Reinganum, M.R., (1986). The puzzling price behavior of treasury bills that mature at the turn of calendar months. Journal of Financial Economics, 16(2), $267-283$.

[28] Santos Silva, J. M. C., and Tenreyro, S. (2006). The log of gravity. Review of Economics and Statistics, 88(4), 641-658.

[29] Santos Silva, J. M. C., and Tenreyro, S. (2010). On the existence of the maximum likelihood estimates in Poisson regression. Economics Letters, 107(2), 310-312.

[30] Simon, D. P. (1994). The treasury's experiment with single-price auctions in the mid1970s: winner's or taxpayer's curse?. Review of Economics and Statistics, 76(4), 754-760.

[31] Skrzypacz, A. and Hopenhayn, H., (2004). Tacit collusion in repeated auctions. Journal of Economic Theory, 114(1), 153-169.

[32] Tenorio, R. (1993). Revenue equivalence and bidding behavior in a multi-unit auction market: an empirical analysis. The Review of Economics and Statistics, 302-314.

[33] Umlauf, S. R. (1993). An empirical study of the Mexican Treasury bill auction. Journal of Financial Economics, 33(3), 313-340.

[34] Wang, J. J., and Zender, J. F. (2002). Auctioning divisible goods. Economic Theory, 19(4), 673-705.

[35] Wooldridge, J. M. (1999). Distribution-free estimation of some nonlinear panel data models. Journal of Econometrics, 90(1), 77-97. 
Figure 1: Number of bidders by auction type

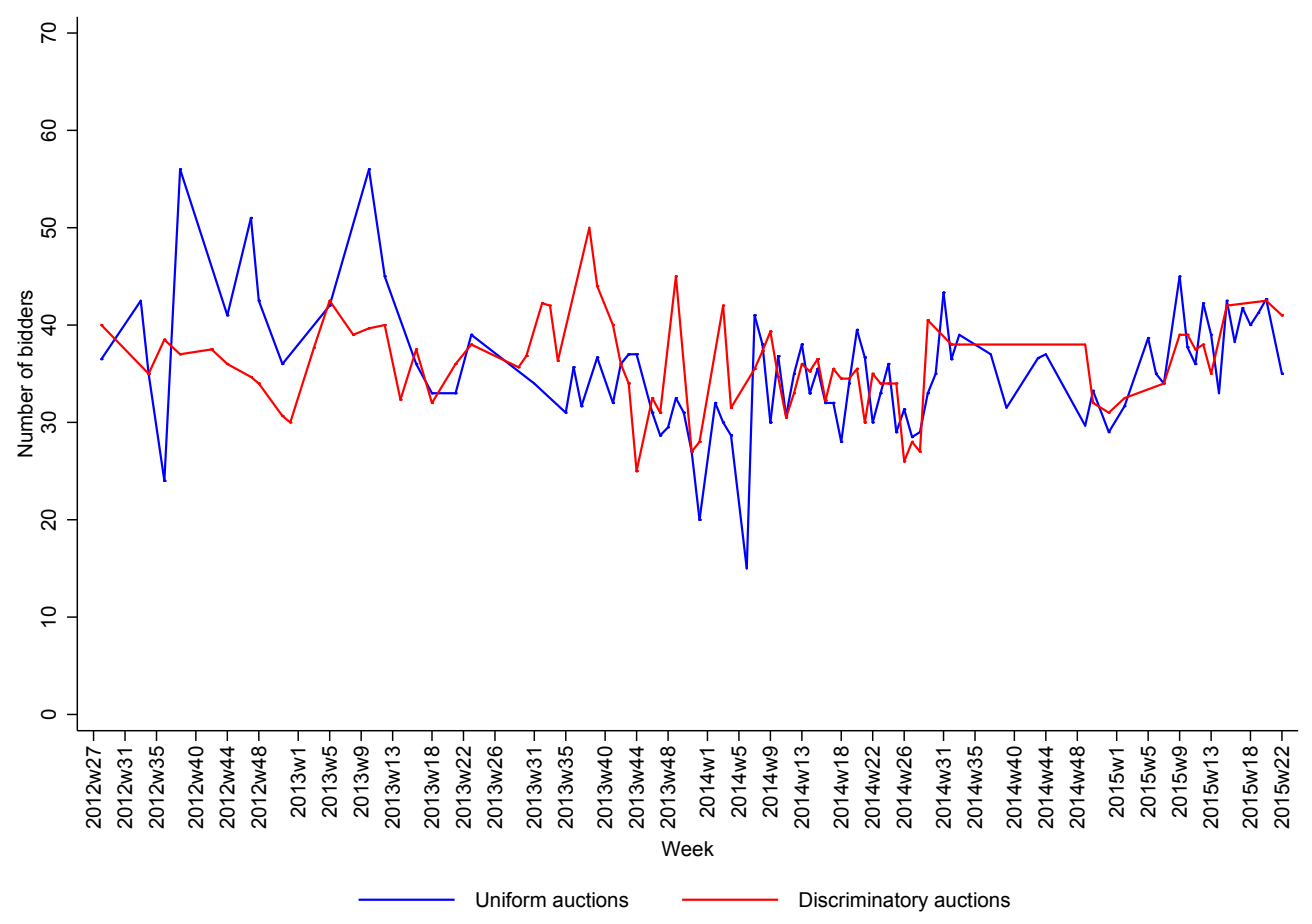

Notes: This figure plots the weekly average number of bidders per auction for all treasury notes by auction format during the experiment. 
Table 1: Chinese government and policy banks' security credit ratings

\begin{tabular}{llllllllll}
\hline Year & \multicolumn{3}{c}{ Fitch } & \multicolumn{3}{c}{ Moody's } & \multicolumn{3}{c}{ Standard \& Poor's } \\
\cline { 2 - 10 } & MOF & CDB & EIB & MOF & CDB & EIB & MOF & CDB & EIB \\
\hline \multicolumn{2}{l}{ Panel A: Long-term } \\
\hline 2012 & A+ & A+ & A+ & Aa3 & Aa3 & Aa3 & AA- & AA- & AA- \\
2013 & A+ & A+ & A+ & Aa3 & Aa3 & Aa3 & AA- & AA- & AA- \\
2014 & A+ & A+ & A+ & Aa3 & Aa3 & Aa3 & AA- & AA- & AA- \\
2015 & A+ & A+ & A+ & Aa3 & Aa3 & Aa3 & AA- & AA- & AA- \\
\hline \multicolumn{2}{l}{ Panel B: Short-term } & & & & & & & \\
\hline 2012 & F1 & F1 & F1 & P-1 & - & - & A-1+ & A-1+ & A-1+ \\
2013 & F1 & F1 & F1 & P-1 & - & - & A-1+ & A-1+ & A-1+ \\
2014 & F1 & F1 & F1 & P-1 & P-1 & - & A-1+ & A-1+ & A-1+ \\
2015 & F1 & F1 & F1 1 & P-1 & P-1 & - & A-1+ & A-1+ & A-1+ \\
\hline
\end{tabular}

This table reports the long-term and short-term credit ratings awarded by Moody's, Standard Poor's, and Fitch to the Chinese government bonds issued by the Minister of Finance (MOF), the Chinese Development Bank (CDB) and the Export- Import Bank (EIB). If a rate was updated in the middle of a calendar year, the updated rate is listed. "--" denotes that no rate was given by a credit rating agency.

Table 2: T-bill distribution by auction type and institution during the experiment

\begin{tabular}{|c|c|c|c|}
\hline \multirow[t]{2}{*}{ Financial institution } & \multicolumn{2}{|c|}{ Auction format } & Total \\
\hline & Discriminatory & Uniform & \\
\hline $\mathrm{CDB}$ & 130 & 139 & 269 \\
\hline EIB & 30 & 49 & 79 \\
\hline Total & 160 & 188 & 348 \\
\hline
\end{tabular}

This table reports number of bonds that were sold by the $\mathrm{CDB}$ and the EIB using uniform and discriminatory auction during the alternating auction-rule experiment. 
Table 3: Example of alternating pattern for the CDB

\begin{tabular}{|c|c|c|}
\hline Date & Maturity in years & Auction mechanism \\
\hline Jan 08, 2013 & $3,5,7$ & Discriminatory \\
\hline Jan 15, 2013 & $3,5,7$ & Uniform \\
\hline \multirow[t]{2}{*}{ Jan 22, 2013} & 5,7 & Discriminatory \\
\hline & 3 & Uniform \\
\hline Jan 29, 2013 & $3,5,7$ & Uniform \\
\hline Feb 05, 2013 & $3,5,7$ & Discriminatory \\
\hline Feb 19, 2013 & $3,5,7$ & Uniform \\
\hline \multirow[t]{2}{*}{ Apr 09, 2013} & 3,7 & Discriminatory \\
\hline & 5 & Uniform \\
\hline Apr 16, 2013 & $3,5,7$ & Uniform \\
\hline \multirow[t]{2}{*}{ Apr 23, 2013} & 3,7 & Discriminatory \\
\hline & 5 & Uniform \\
\hline May 07, 2013 & $3,5,7$ & Uniform \\
\hline \multirow[t]{2}{*}{ May 14, 2013} & 3,7 & Discriminatory \\
\hline & 5 & Uniform \\
\hline May 21, 2013 & $3,5,7$ & Uniform \\
\hline \multirow[t]{2}{*}{ May 28, 2013} & 3,7 & Discriminatory \\
\hline & 5 & Uniform \\
\hline Jun 04, 2013 & $3,5,7$ & Uniform \\
\hline Jun 18, 2013 & $3,5,7$ & Discriminatory \\
\hline Jul 02, 2013 & $3,5,7$ & Discriminatory \\
\hline Jul 09, 2013 & $3,5,7$ & Uniform \\
\hline Jul 16, 2013 & $3,5,7$ & Discriminatory \\
\hline Jul 23, 2013 & $3,5,7$ & Uniform \\
\hline Jul 30, 2013 & $3,5,7$ & Discriminatory \\
\hline
\end{tabular}

This table reports the stylized pattern of this alternating auction-rule experiment conducted by the CDB. The table shows that the auction mechanism alternated between discriminatory and uniform auction rules. Note that all bills (maturity less or equal to one year) and bonds (maturity) equal or more than 10 years) were sold using uniform. The alternating auction-rule experiment period for CDB was from May 2012 - July 2014. 
Table 4: Example of randomization patterns for the EIB

\begin{tabular}{|c|c|c|c|}
\hline Date & Bond ID & Maturity in years & Auction mechanism \\
\hline \multicolumn{4}{|c|}{ Panel A: Randomzing by date } \\
\hline Jul 31, 2013 & & $2(t)$ & Discriminatory (Uniform) \\
\hline Aug 15, 2013 & & $2(t)$ & Discriminatory (Uniform) \\
\hline Sep 24, 2013 & & $2(t)$ & Discriminatory (Uniform) \\
\hline Oct 21,2013 & & $2(t)$ & Uniform (Discriminatory) \\
\hline Nov 04,2013 & & $2(t)$ & Uniform (Discriminatory) \\
\hline Apr 11, 2014 & & $3(t)$ & Discriminatory (Uniform) \\
\hline May 15,2014 & & $3(t)$ & Uniform (Discriminatory) \\
\hline May 23, 2014 & & $3(t)$ & Discriminatory (Uniform) \\
\hline Jun 06, 2014 & & $3(t)$ & Uniform (Discriminatory) \\
\hline \multicolumn{4}{|c|}{ Panel B: Randomzing by bond } \\
\hline Nov 28,2014 & 14 EXIM 78 (initial) & 2 & Discriminatory \\
\hline Dec 04, 2014 & 14 EXIM 78 (reissue) & 2 & Uniform \\
\hline Dec 17, 2014 & 14 EXIM 78 (reissue) & 2 & Discriminatory \\
\hline Apr 15, 2015 & 15 EXIM 09 (initial) & 3 & Uniform \\
\hline Apr 24,2015 & 15 EXIM 09 (reissue) & 3 & Uniform \\
\hline Apr 30, 2015 & 15 EXIM 09 (reissue) & 3 & Uniform \\
\hline May 06, 2015 & 15 EXIM 09 (reissue) & 3 & Discriminatory \\
\hline May 13, 2015 & 15 EXIM 09 (reissue) & 3 & Discriminatory \\
\hline May 21, 2015 & 15 EXIM 09 (reissue) & 3 & Discriminatory \\
\hline
\end{tabular}

This table reports the stylized pattern of this alternating auction-rule experiment conducted by the EIB. The EIB conducted bi-weekly (or often much longer interval) auctions, held typically on Fridays, usually with two to four different maturities. The EIB alternated the two different auction rules for different maturities (Panel A - Alternating auction rule by date) and, in the latter half of the experimental period, the institution used the two auction rules on the same type of bond when reissuing (Panel B - Alternating auction rule by bond type). The alternating auction-rule experiment period for CDB was from July 2013 - May 2015. The index $t$ in the upper panel denotes other maturity in years that were auctioned off in the same day. 
Table 5: Results of the balance test for covariates

\begin{tabular}{lccc}
\hline Variable & Uniform & Discriminatory & $t$-Value \\
\hline Market yield of Chinese bonds one day before the auction date & 3.685 & 3.683 & 0.044 \\
& {$[3.617,3.753]$} & {$[3.612,3.753]$} & \\
Log of duration & 1.391 & 1.417 & -0.703 \\
& {$[1.347,1.435]$} & {$[1.357,1.477]$} & \\
Log of demand/supply & 0.886 & 0.888 & -0.093 \\
& {$[0.830,0.941]$} & {$[0.858,0.919]$} & \\
Volatility & 0.026 & 0.029 & -1.604 \\
& {$[0.023,0.028]$} & {$[0.026,0.032]$} & \\
Log value of maturing bonds by institution for a given month & 14.505 & 14.672 & -1.030 \\
& {$[14.265,14.746]$} & {$[14.461,14.883]$} & -0.322 \\
First and last week of the month & 0.824 & 0.838 & $-0.780,0.895]$ \\
\end{tabular}

This table reports the mean, the $95 \%$ confidence intervals and the calculated t-values for prior day's yield curve, duration, market volatility, and value of maturing bonds by the institution for a given month of the CDB and the EIB government bonds sold through uniform and discriminatory auctions. The variable duration refers to Macaulay duration, which is the weighted average term to maturity of the cash flows from a bond. The $p$-values are denoted by asterisks according to the following scheme: ${ }^{* * *} p<0.01,{ }^{* *} p<0.05,{ }^{*} p<0.1$. 
Table 6: Regression results for number of bidders

\begin{tabular}{|c|c|c|c|c|}
\hline \multirow[t]{2}{*}{ Variable } & \multicolumn{4}{|c|}{ Number of bidders } \\
\hline & \multicolumn{2}{|c|}{ PPML } & \multicolumn{2}{|c|}{ OLS } \\
\hline \multirow[t]{2}{*}{ Discriminatory auctions } & 0.001 & 0.001 & 0.017 & 0.005 \\
\hline & $(0.014)$ & $(0.014)$ & $(0.025)$ & $(0.016)$ \\
\hline \multirow[t]{2}{*}{ Floating bond } & $-0.053^{* *}$ & & $-0.051^{*}$ & \\
\hline & $(0.026)$ & & $(0.031)$ & \\
\hline Market yield of Chinese bonds & 0.015 & 0.008 & 0.011 & -0.001 \\
\hline one day before the auction date & $(0.025)$ & $(0.025)$ & $(0.028)$ & $(0.029)$ \\
\hline \multirow[t]{2}{*}{ Log of duration } & -0.030 & -0.025 & -0.032 & -0.025 \\
\hline & $(0.019)$ & $(0.020)$ & $(0.024)$ & $(0.026)$ \\
\hline \multirow[t]{2}{*}{ Log of demand/supply } & $0.244^{* * *}$ & $0.227^{* * *}$ & $0.265^{* * *}$ & $0.246^{* * *}$ \\
\hline & $(0.025)$ & $(0.026)$ & $(0.034)$ & $(0.035)$ \\
\hline \multirow[t]{2}{*}{ Volatility } & 0.065 & -0.106 & 0.339 & -0.057 \\
\hline & $(0.265)$ & $(0.273)$ & $(0.508)$ & $(0.305)$ \\
\hline Log of time lag between auctions & 0.016 & -0.005 & 0.016 & -0.007 \\
\hline by institution & $(0.011)$ & $(0.015)$ & $(0.013)$ & $(0.017)$ \\
\hline Log value of maturing bonds by & -0.000 & -0.002 & -0.001 & -0.002 \\
\hline institution for a given month & $(0.005)$ & $(0.006)$ & $(0.006)$ & $(0.007)$ \\
\hline Institution effects & Yes & Yes & Yes & Yes \\
\hline First and last week of the month & Yes & Yes & Yes & Yes \\
\hline Month and year effects & Yes & Yes & Yes & Yes \\
\hline Market drift & Yes & Yes & Yes & Yes \\
\hline Observations & 348 & 301 & 348 & 301 \\
\hline $\mathrm{R}^{2}$ & 0.570 & 0.593 & 0.541 & 0.557 \\
\hline
\end{tabular}

This table presents the estimates for the number of bidders in an auction, controlling for auction type, institutions, market conditions, time gap between auctions by institutions, demand and supply ratio of bonds, institution effects, first and last week of the month, monthly effects, year effects, and market drift. The variable duration refers to Macaulay duration, which is the weighted average term to maturity of the cash flows from a bond. We estimate this using the Poisson Pseudo Maximum Likelihood (PPML) method and also using OLS. Robust standard errors are in parentheses, and $p$-values are denoted by asterisks according to the following scheme: ${ }^{* * *} p<0.01,{ }^{* *} p<0.05,{ }^{*} p<0.1$. 


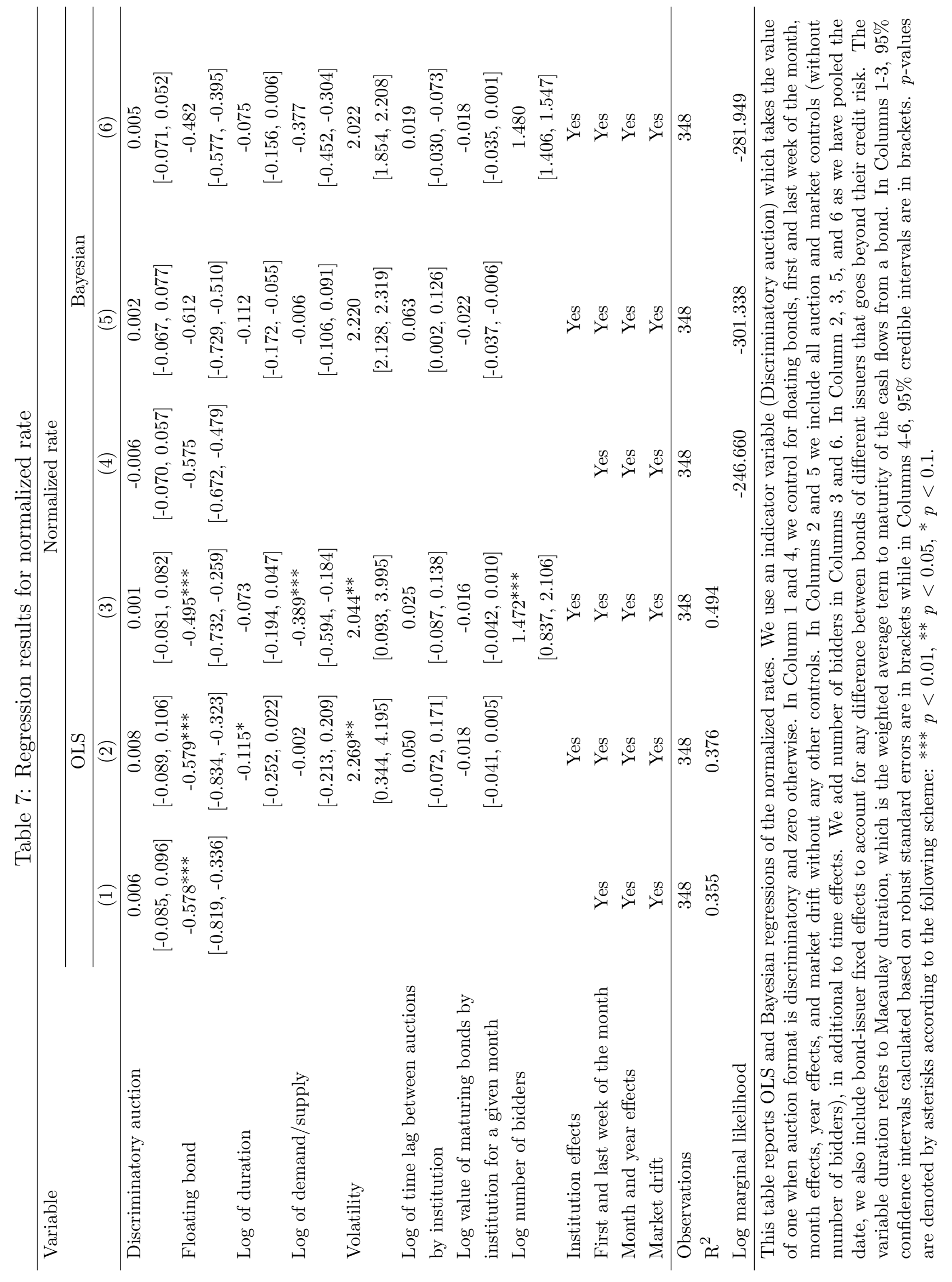


Table 8: Regression results for normalized rates with highest and lowest discriminatory auction rates

\begin{tabular}{lcccc}
\hline \multirow{2}{*}{ Variable } & \multicolumn{4}{c}{ Normalized rate } \\
\cline { 2 - 5 } & \multicolumn{3}{c}{ OLS } & \multicolumn{2}{c}{ Bayesian } \\
\cline { 2 - 5 } & Highest & Lowest & Highest & Lowest \\
\cline { 2 - 5 } & $(1)$ & -0.007 & 0.036 & -0.012 \\
\hline Discriminatory auction & 0.028 & {$[2)$} & {$[-0.066,0.042]$} \\
Floating bond & {$[-0.053,0.110]$} & {$[-0.089,0.074]$} & {$[-0.033,0.101]$} & -0.476 \\
Auction and market controls & $-0.491^{* * *}$ & $-0.497^{* * *}$ & -0.488 & {$[-0.571,-0.386]$} \\
Institution effects & {$[-0.727,-0.256]$} & {$[-0.733,-0.260]$} & {$[-0.565,-0.414]$} & Yes \\
First and last week of the month & Yes & Yes & Yes & Yes \\
Month and year effects & Yes & Yes & Yes & Yes \\
Market drift & Yes & Yes & Yes & Yes \\
\hline Observations & Yes & Yes & Yes & Yes \\
$\mathrm{R}^{2}$ & 348 & 348 & 348 & 348 \\
Log marginal likelihood & 0.499 & 0.492 & & -282.579 \\
\hline
\end{tabular}

This table reports OLS and Bayesian regressions of normalized rates with highest and lowest discriminatory auction bids. Our dependent variables is the auction-specific normalized highest (Columns 1 and 3) and the lowest (Columns 2 and 4) winning rate on a given date. In all columns, we control for auction format, other auction, and market characteristics in addition to month effects, year effects, market drift, and bond-issuer fixed effects. In Columns 1-2, 95\% confidence intervals calculated based on robust standard errors are in brackets while in $3-4,95 \%$ credible intervals are in brackets. $p$-values are denoted by asterisks according to the following scheme: ${ }^{* * *} p<0.01,{ }^{* *} p<0.05,{ }^{*} p<0.1$. 


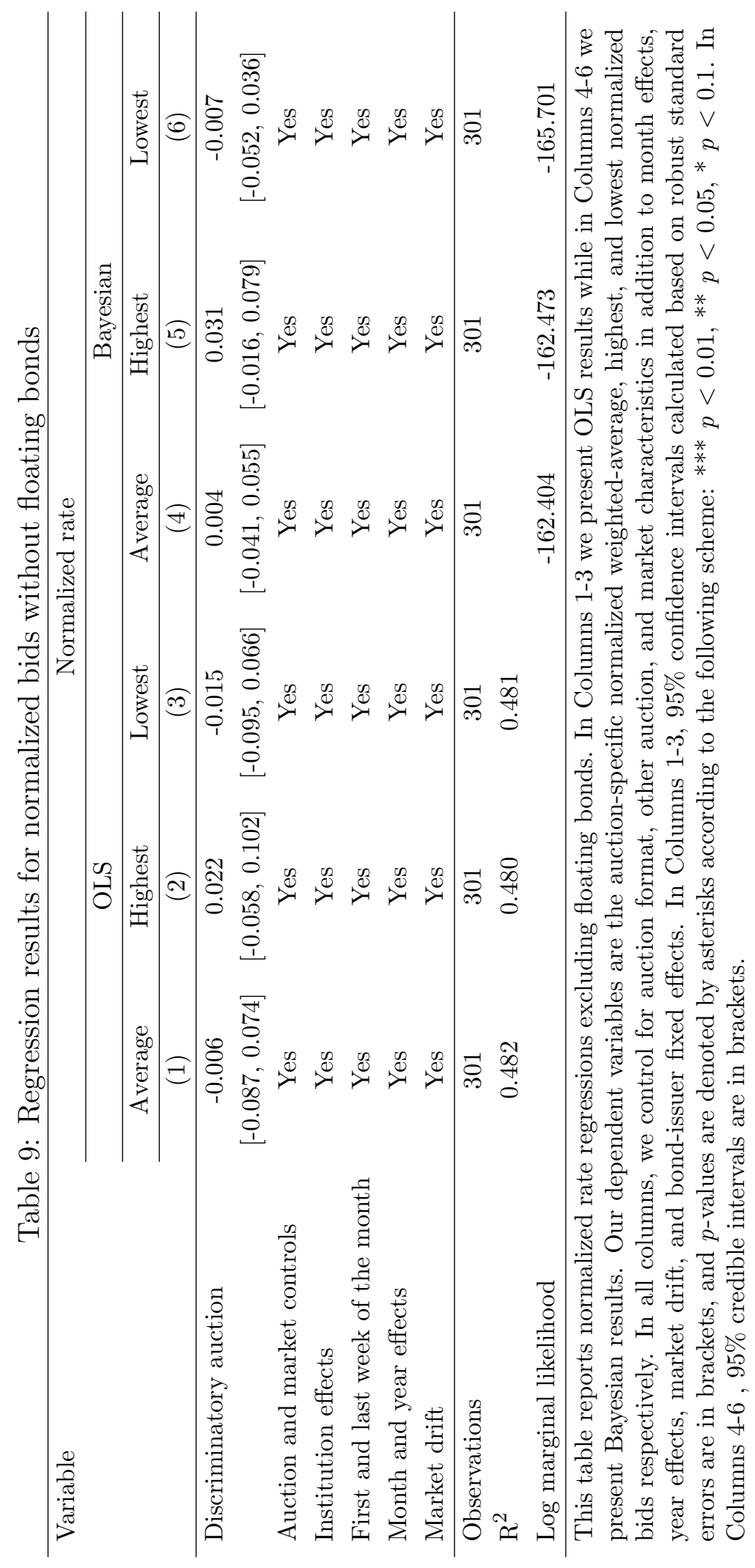


Table 10: Regression results for normalized rate in the first- and second-half of the experiment

\begin{tabular}{lcccc}
\hline Variable & \multicolumn{4}{c}{ Normalized rate } \\
\cline { 2 - 5 } & \multicolumn{3}{c}{ OLS } & \multicolumn{3}{c}{ Bayesian } \\
\cline { 2 - 5 } & First-half & Second-half & First-half & Second-half \\
\cline { 2 - 5 } & $(1)$ & $(2)$ & $(3)$ & $(4)$ \\
\hline Discriminatory auction & -0.021 & 0.009 & -0.063 & 0.005 \\
Floating bond & {$[-0.184,0.142]$} & {$[-0.090,0.109]$} & {$[-0.150,0.026]$} & {$[-0.072,0.071]$} \\
& $-0.765^{* * *}$ & 0.160 & -0.830 & 0.183 \\
Auction and market controls & {$[-1.055,-0.475]$} & {$[-0.342,0.662]$} & {$[-0.961,-0.703]$} & {$[0.100,0.268]$} \\
Institution effects & Yes & Yes & Yes & Yes \\
First and last week of the month & Yes & Yes & Yes & Yes \\
Month and year effects & Yes & Yes & Yes & Yes \\
Market drift & Yes & Yes & Yes & Yes \\
\hline Observations & Yes & Yes & Yes & Yes \\
$\mathrm{R}^{2}$ & 148 & 200 & 148 & 200 \\
Log marginal likelihood & 0.524 & 0.547 & & -169.182 \\
\hline
\end{tabular}

This table reports OLS and Bayesian regressions for the normalized rates auctioned off in the first- and the second-half of the experiment. In all Columns, we control for all auction format, other auction, and market controls in addition to floating bonds, monthly effects, year effects, market drift, and bond-issuer fixed effects as in Table 7 Column 3 and 6 . In Columns 1 and 2, 95\% confidence intervals calculated based on robust standard errors are in brackets, and $p$-values are denoted by asterisks according to the following scheme: ${ }^{* * *} p<0.01,{ }^{* *} p<0.05,{ }^{*} p<0.1$. In Columns 3 and $4,95 \%$ credible intervals are in brackets. 
Table 11: Results for number of bidders during the experiment

\begin{tabular}{lcc}
\hline Variables & \multicolumn{2}{c}{ Number of bidders } \\
\cline { 2 - 3 } & PPML & OLS \\
\cline { 2 - 3 } & $(1)$ & $(2)$ \\
\hline Discriminatory auction & -0.074 & -2.194 \\
& $(0.053)$ & $(1.854)$ \\
Second half & -0.008 & -0.019 \\
& $(0.026)$ & $(0.982)$ \\
Second half $\times$ Discriminatory auctions & 0.011 & 0.114 \\
& $(0.030)$ & $(1.114)$ \\
Auction and market controls & Yes & Yes \\
Institution effects & Yes & Yes \\
First and last week of the month & Yes & Yes \\
Month and year effects & Yes & Yes \\
Market drift & Yes & Yes \\
\hline Observations & 348 & 348 \\
$\mathrm{R}^{2}$ & 0.576 & 0.590 \\
\hline
\end{tabular}

This table presents the estimates for the number of bidders in an auction, controlling auction type, institutions, market conditions, the time gap between auctions by institutions, demand, and supply ratio of bonds, and institution effects which are denoted by auction and market controls. Additionally, we have included month effects, year effects, and market drift. Robust standard errors are in brackets, and $p$-values are denoted by asterisks according to the following scheme: ${ }^{* * *} p<0.01,{ }^{* *} p<0.05,{ }^{*} p$ $<0.1$. 


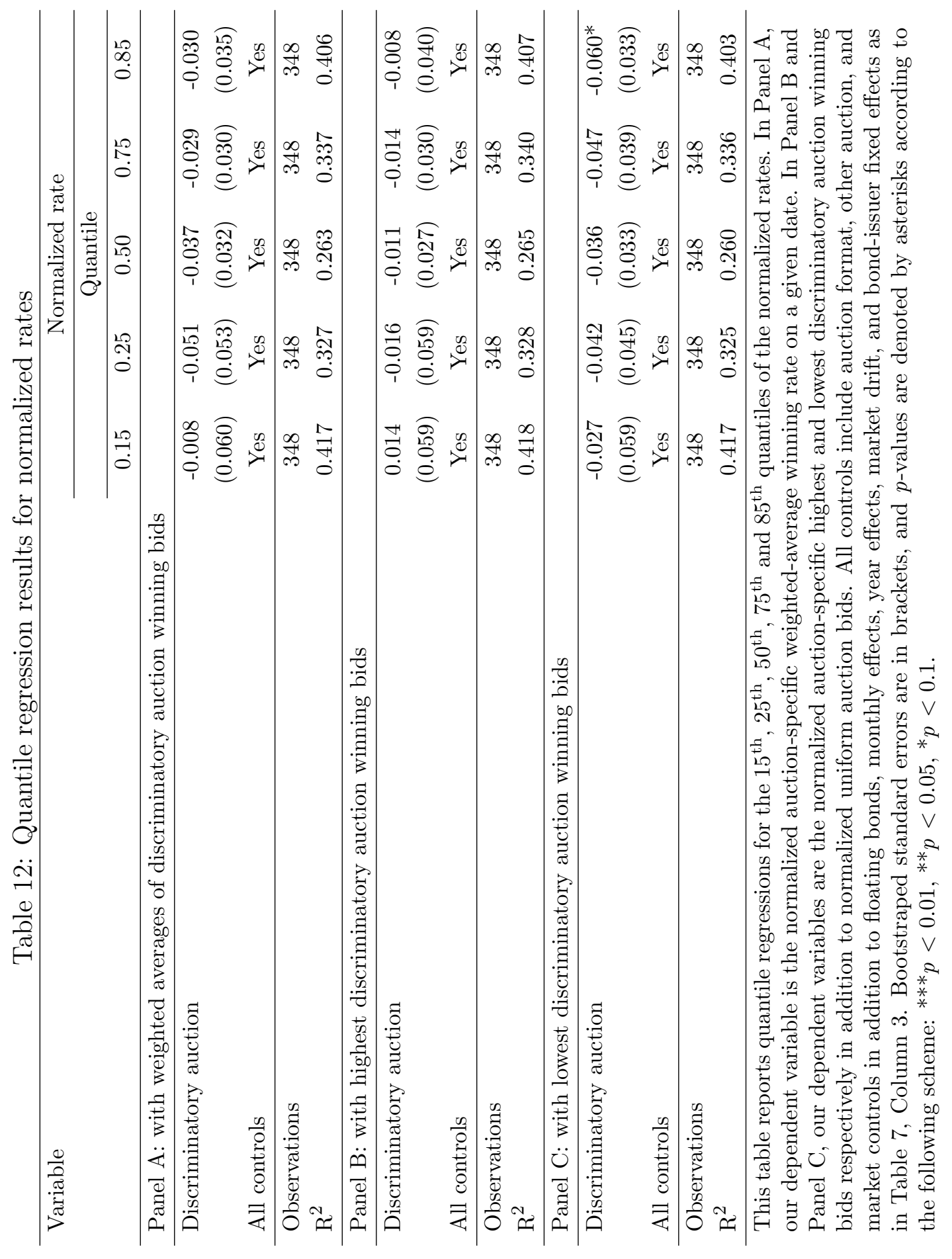




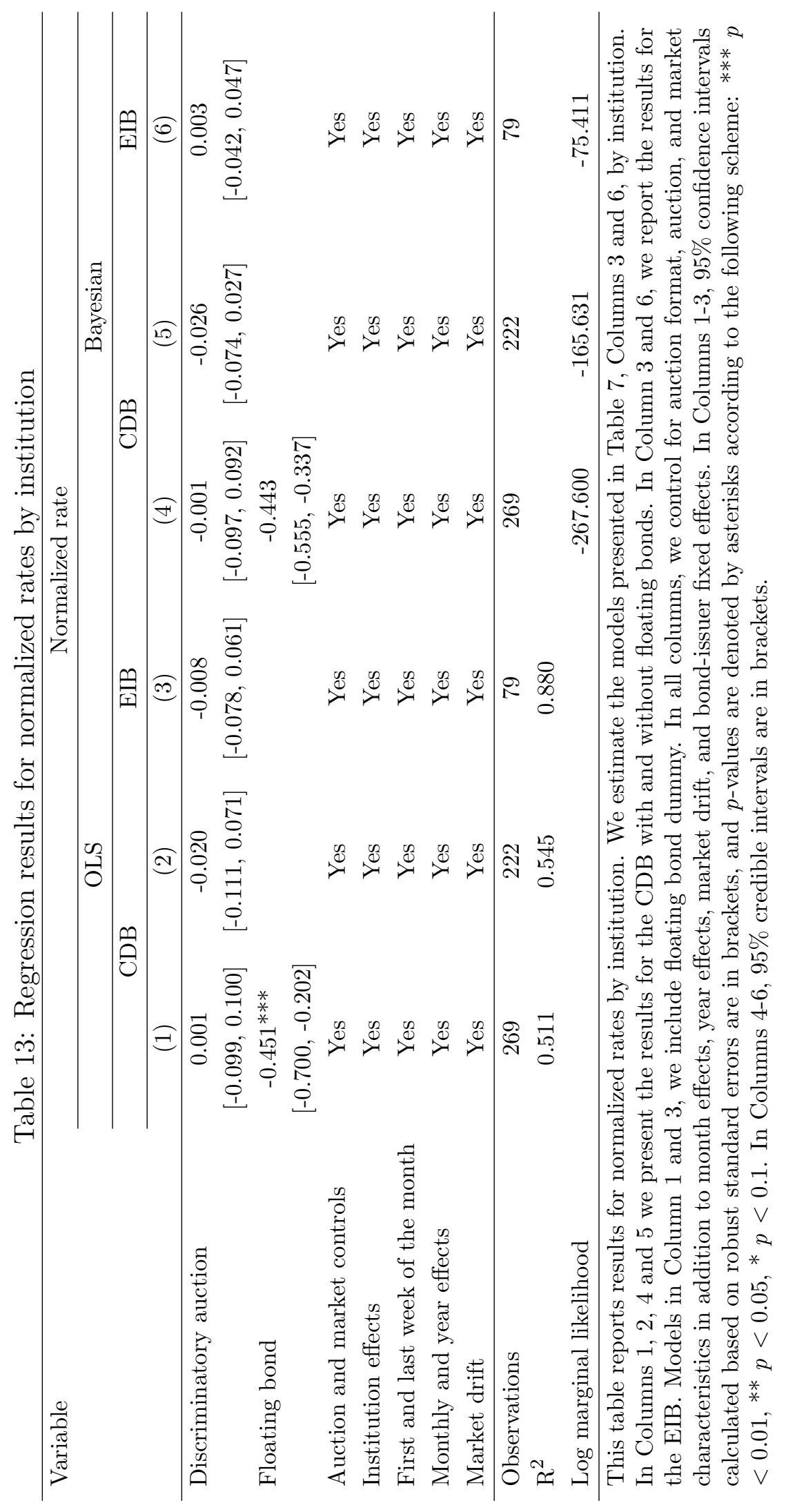




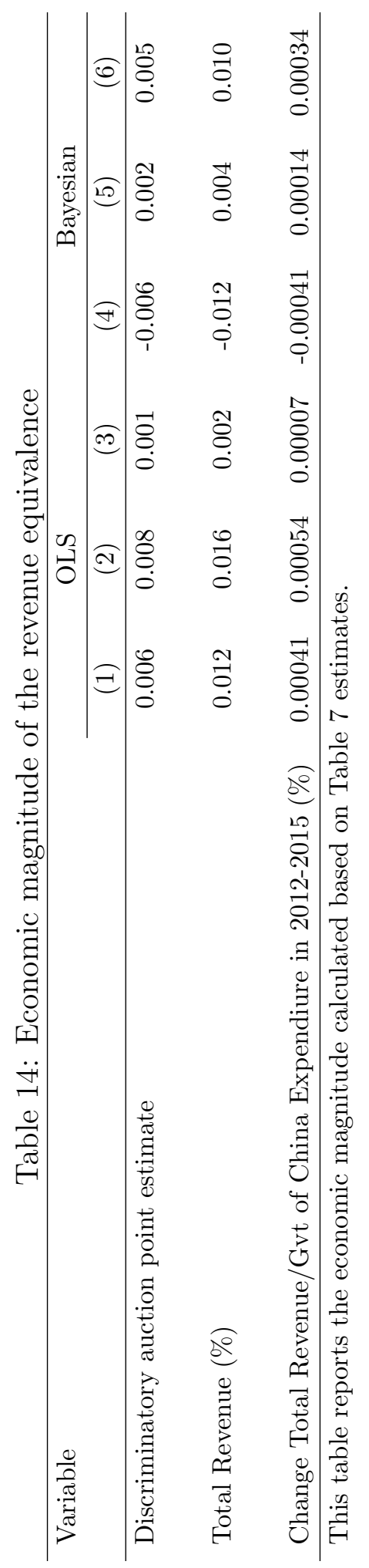


Appendix A 
Table A.1: Variable description

\begin{tabular}{|c|c|}
\hline Variable & Description \\
\hline Discriminatory auctions & $\begin{array}{l}\text { This variable takes the value one when the auction format is discriminatory } \\
\text { and zero when the auction mechanism is uniform. }\end{array}$ \\
\hline Floating bonds & $\begin{array}{l}\text { The floating bonds variable is a binary indicator, which is equal to one if } \\
\text { an auction is for floating bond, zero otherwise. Note that all of the floating } \\
\text { bonds are sold through the uniform-price format only. }\end{array}$ \\
\hline Market yield of Chinese bonds & This variable is the publicly announced yield curve rates by the CCDC. \\
\hline one day before the auction date & $\begin{array}{l}\text { Each business day, the CCDC publicly announces the yield curves for bonds } \\
\text { issued by the CDB and EIB by maturity, which are based on previous resale } \\
\text { market transactions. These yield curves provide official benchmarks to } \\
\text { general investors. }\end{array}$ \\
\hline Duration & $\begin{array}{l}\text { The duration variable refers to Macaulay duration, which is the weighted } \\
\text { average term to maturity of the cash flows from a bond. A similar duration } \\
\text { variable is used by Simon (1994). }\end{array}$ \\
\hline Demand/supply & $\begin{array}{l}\text { This variable is the ratio of the total amount of tenders divided by a supply } \\
\text { volume. This variable controls the strength of demand and the degree of } \\
\text { competitions in an auction. A similar measure is used by Cordy } \\
\text { (1999) and Goldreich (2007). In our sample, total demand was always more } \\
\text { than the supply. }\end{array}$ \\
\hline Lag time between auctions & $\begin{array}{l}\text { This variable measures the business days since the last auction held by } \\
\text { an institution. }\end{array}$ \\
\hline $\begin{array}{l}\text { Value of maturing bonds by } \\
\text { institution for a given month }\end{array}$ & $\begin{array}{l}\text { This is the sum of face values, which the issuer has to pay in a specific month. } \\
\text { This variable controls the possibility that financial institutions may recycle } \\
\text { their liquidity obtained through matured securities to bid for new issuance. }\end{array}$ \\
\hline Number of bidders & This is the number of bidders in an auction. \\
\hline CDB & $\begin{array}{l}\text { This variable is a binary indicator variable that takes the value of one when } \\
\text { auctions are let by the CDB and zero otherwise. }\end{array}$ \\
\hline First and last week of the month & $\begin{array}{l}\text { This indicator variable is equal to one if the auction date takes place seven } \\
\text { days before or seven days after the end of the month, and equal to zero } \\
\text { otherwise. }\end{array}$ \\
\hline Market drift & $\begin{array}{l}\text { This variable is constructed by counting the number of weeks since the start of the } \\
\text { experiment by dividing each week by the number of total weeks in which the } \\
\text { CDB and EIB conducted their market experiment. Simon (1994) notes that a } \\
\text { market-drift variable controls for gradual unobservable changes that bidders face } \\
\text { during the market experiment period. Although a model of long-term relationships } \\
\text { with dynamic trade-offs is beyond the scope of this study, other studies point out that } \\
\text { a repeated auction environment can sustain a variety of strategies in equilibria (see e.g. } \\
\text { Skrzypacz and Hopenhayn, } 2004) \text {, and this time-shifting variable parsimoniously } \\
\text { controls for potential gradual changes in long-term interactions among bidders, } \\
\text { regardless of the auction formats. }\end{array}$ \\
\hline
\end{tabular}


Table A.2: Bidder behavior in uniform auctions during and after the experiment

\begin{tabular}{lcc}
\hline Variable & Number of bidders & Normalized rate \\
\hline After (12 months) & 0.013 & -0.061 \\
& $(0.024)$ & $(0.071)$ \\
Floating bond & -0.044 & $-0.556^{* * *}$ \\
& $(0.036)$ & $(0.121)$ \\
Market yield of Chinese bonds one day before the auction date & $-0.051^{* *}$ & \\
& $(0.023)$ & Yes \\
Other controls & Yes & 389 \\
\hline Observations & 389 & 0.353 \\
$\mathrm{R}^{2}$ & 0.394 & \\
\hline
\end{tabular}

This table presents the estimates for the number of bidders and normalized rates in auctions controlling for after experiment period, institutions, market conditions, time gap between auctions by institutions, demand and supply ratio of bonds, institution effects, and all other market and time controls. The Column 1 is estimated using the Poisson Pseudo Maximum Likelihood (PPML) method and Column 2 is estimated using OLS. Robust standard errors are in parentheses, and $p$-values are denoted by asterisks according to the following scheme: ${ }^{* * *} p<0.01,{ }^{* *} p<0.05,{ }^{*} p<0.1$. 